\section{Effect of Metal Primers on Bond Strength of a Composite Resin to Nickel-Chrome Metal Alloy}

Gabriel Nima, Paulo Vitor Campos Ferreira, Andreia Bolzan de Paula, Simonides Consani, Marcelo Giannini
Department of Restorative Dentistry, Operative Dentistry Division, Piracicaba Dental School, UNICAMP - Universidade Estadual de Campinas, Piracicaba, SP, Brazil

Correpondence: Gabriel Nima, Av. Limeira, 901 - Bairro Areião, 13414-903 Piracicaba, SP, Brasil. Tel: +55-19-2106-5347. e-mail: gabrieln_b@yahoo.com

\begin{abstract}
This study evaluated the effects of three metal primers and one multi-mode adhesive system on the shear bond strength (SBS) of a flowable composite resin to nickel-chrome metal alloy ( $\mathrm{Ni}-\mathrm{Cr})$. Ninety plates were cast from $\mathrm{Ni}-\mathrm{Cr}$ and divided in nine groups $(\mathrm{n}=10)$. The surfaces were sandblasted with $\mathrm{Al}_{2} \mathrm{O}_{3}$ and primed with three adhesive primers: Alloy Primer (AP), Universal Primer (TP) and RelyX Ceramic Primer (CP), and a multimode adhesive (Scotchbond Universal, SU). The Adper Single Bond Plus (SB) and SU adhesives were also combined with adhesive primers. Control group did not have any surface treatment. The groups were: $A P, A P+S B, A P+S U, T P+S B, T P+S U, C P+S B, C P+S U$ and SU. Composite cylinders were built on alloy surface. After $24 \mathrm{~h}$, half the specimens were subjected to SBS and the other half to thermal cycling before testing. Data were analyzed by two-way ANOVA and Tukey's test $(\alpha=0.05)$. Failure modes were assessed by SEM observation. Higher SBS were obtained with AP and TP combined with adhesives at $24 \mathrm{~h}$ and the lowest one for control group. Thermocycling reduced SBS for AP, CP+SU and SU. Combination between TP and SU resulted in the highest SBS after the thermocycling. TP groups showed all types of failures and high incidence of mixed failures. The use of AP and UP metal primers before application of SU and SB adhesive systems increased the SBS of composite to $\mathrm{Ni}-\mathrm{Cr}$. These combinations between metal primers and adhesives had the highest SBS after thermocycling.
\end{abstract}

Key Words: metal alloy, primer, resin composite, shear bond strength, dental prosthesis repair.

\section{Introduction}

Porcelain-fused-to-metal (PFM) indirect restorations are still considered a good option for oral rehabilitation, for its aesthetic quality and high resistance $(1,2)$. Due to its high elasticity module relative to gold, nickel-chrome (Ni$\mathrm{Cr}$ ) alloy is suitable for metallic framework in fixed partial denture, single crowns, implant connections, etc. Some failures of ceramic-fused-to-metal indirect restorations are related to ceramic fractures with exposure of the metal substructure, with aesthetic and functional damages. According to Hickel et al. (3), the major causes of porcelain fractures are due to laboratory preparations and incorrect treatment planning, like inadequate interocclusal space for the metal substructure and porcelain cover, improper design preparation, impact and fatigue load (1-3).

Ideally, replacement of the restoration is desirable, but sometimes the intraoral repair with composite resin is an option with the advantage of shorter time procedure and low cost (4). In attempt to improve the bonding of composites to alloy, chemical and mechanical bonding techniques have been proposed to treat the dental alloys surface in order to obtain adequate bonding (5). Silicoater MD (Heraeus Kulzer GmbH, Hanau, Germany) and Rocatec
(3M ESPE, St Paul, MN, USA) have also been reported to be effective, but they require special equipment (6). Metal primers do not require special equipment or complicated manipulations. They contain active monomers that provide chemical bonding between the composite resin and oxide on the metal alloy surfaces $(7,8)$.

The 4-META (4-methacryloyloxyethy trimellitate anhydride) was the first monomer used for adhesion to metal. It was used to improve the bonding to metal castings, eliminating the need for mechanical retention (9). New monomers containing phosphoric and carboxylic acid groups have been synthesized as adhesion promoters for metal alloys, like 10-methacryloyloxydecyl dihydrogenphosphate (10-MDP) and 1-methacryloxy1,1-undecanecarboxylic acid (MAC-10). Other functional monomers containing sulfur compounds, 6-(4-vinylbenzylpropyl)amino-1,3,5-triazine-2,4-ditione (VBATDT) and 6-methacryloxyhexyl-2-thiouracil-5caboxylate (MTU-6) have been successfully indicated for bonding to precious metal alloys $(8,10,11)$.

Dual function primers are composed of sulfurcontaining monomers and phosphoric or carboxylic 
monomers, and are designed for both noble and base metal alloys $(6,12,13)$. These primers may contain MDP, VBATDT, MTU-6 or MAC- 10 and combinations of two of these functional monomers. In recent years, "Universal" or "Multi-mode" adhesives have been introduced and also are indicated to bond composites to metal alloys. However, investigations have focused on adhesion to enamel and dentin $(14,15)$, and no information regarding the bonding of universal alloy primers and adhesives to metal alloys was provided.

Thus, the purpose of this study was evaluate the effects of three adhesive primers and one multi-mode adhesive system on the shear bond strength (SBS) of flowable composite to $\mathrm{Ni}-\mathrm{Cr}$ alloy, after thermal cycling or not of samples. The null hypotheses tested were that (1) SBS would not be influenced by the primers or multimode adhesive and (2) thermocycling would not reduce the SBS.

\section{Material and Methods}

The materials used are in Table 1. Three adhesive primers were used: RelyX Ceramic Primer (3M ESPE; St Paul, MN, USA), Alloy Primer (Kuraray Noritake Dental Inc.; Tokyo, Japan) and Universal Primer (Tokuyama Dental Corp.; Tokyo, Japan). The primers were combined with two dental adhesives (Adper Single Bond Plus and Scotchbond Universal; 3M ESPE).

Ninety rectangular wax patterns $(8 \times 10 \times 2 \mathrm{~mm})$ were prepared and cast using nickel-chrome alloy (Verabond II; Aalba Dental Inc., Fairfield, CA, USA), according to manufacturer's instructions. The casting blocks were embedded in a self-polymerizing acrylic resin (Vipi Flash; Vipi Produtos Odontológicos, Pirassununga, SP, Brazil) using 1/2" diameter rigid PVC tubes (Tigre; Rio Claro, SP, Brazil). One side had the metal surface exposed, used for bonding of flowable composite by different bonding agents and techniques. The metal alloy surfaces of all samples were polished with 180-grit wet silicon carbide abrasive paper for 30 s (Norton; Guarulhos, SP, Brazil), sandblasted with 50 $\mu \mathrm{m}$ aluminum oxide (nozzle at $10 \mathrm{~mm}$ from the surface at 60 psi) for 10 s (Microetcher IITM; Danville Engineering Inc., San Ramon, CA, USA) and placed in an ultrasonic cleanser (USC 1400; Unique, Indaiatuba, SP, Brazil) for 15 min.

Samples were randomly divided in nine groups $(n=10)$, according to the used primers and adhesive systems. The experimental groups are in Table 2 and described as follows: Control group (untreated), AP (Alloy Primer), AP+SB (Alloy Primer + Adper Single Bond Plus), AP+SU (Alloy Primer + Scotchbond Universal), UP+SB (Universal Primer + Adper Single Bond Plus), UP+SU (Universal Primer + Scotchbond Universal), $\mathrm{CP}+\mathrm{SB}$ (Ceramic Primer + Adper Single Bond Plus), $\mathrm{CP}+\mathrm{SU}$ (Ceramic Primer + Scotchbond Universal) and SU (Scotchbond Universal)

All primers and adhesive were applied according to manufacturers' instructions. Light-activation was performed with Bluephase LED curing unit (Ivoclar Vivadent; Schaan, Liechtenstein) in standard irradiation mode $\left(1,000 \mathrm{~mW} / \mathrm{cm}^{2}\right)$. After treating or not the $\mathrm{Ni}-\mathrm{Cr}$ alloy surface, six silicone molds were positioned over the alloy surface (cylindrical hole $1 \mathrm{~mm}$ diameter and $1 \mathrm{~mm}$ high) and flowable resin (Filtek Supreme Ultra Flowable Restorative; 3M ESPE) was poured into the holes to fill them. The flowable composite was used to facilitate the filling of mold hole, which has small dimensions. The composite resin was light activated for $20 \mathrm{~s}$. Afterwards, the silicone molds were carefully removed to expose the composite cylinders and to obtain 6 composite cylinders bonded to alloy surface.

The samples were stored in water at $37{ }^{\circ} \mathrm{C}$ for $24 \mathrm{~h}$.

Table 1. Compositions and lot numbers of the materials

\begin{tabular}{lc}
\hline Material & Composition (batch number) \\
\hline Verabond II & $76.5 \% \mathrm{Ni}, 11.5 \% \mathrm{Cr}, 3.5 \% \mathrm{Mo}, \mathrm{Nb}, \mathrm{Al}, \mathrm{Si}, \mathrm{Ti}$ \\
Adper Single Bond Plus & Bis-GMA, HEMA, polyalkenoic acid copolymer, photoinitiator system, water, ethanol (N544888) \\
Scotchbond Universal & MDP, dimethacrylate resins, HEMA, Vitrebond copolymer, filler, ethanol, water, initiators, silane. (569736) \\
RelyX Ceramic Primer & MPS, ethanol, water (1435200336) \\
Alloy Primer & VBATDT, MDP, acetone (0444CD) \\
Universal Primer & $\begin{array}{l}\text { Primer A: Bis-GMA, TEGDMA, BHT, silane A174, MTU-6, ethanol (016E04) } \\
\text { Filtek Supreme Ultra }\end{array}$ \\
Flowable Restorative & Bis-GMA, TEGDMA, Bis-EMA, dimethacrylate polymer, silane-treated ceramic, silane- \\
treated silica, ytterbium trifluoride, titanium oxide (1505500652)
\end{tabular}

Abbreviations: BHT: Butylhydroxytoluene; Bis-EMA: Ethoxylated bisphenol A glycol dimethacrylate; Bis-GMA: Bisphenol A diglycidyl methacrylate; HEMA: 2-hydroxyethyl methacrylate; MAC-10: 1-methacryloxy-1,1-undecanecarboxylic acid; MDP: 10-methacryloyloxydecyl dihydrogenphosphate; MPS: Gama-methacryloxypropyl trimethoxysilane; MTU-6: 6-methacryloxyhexyl-2-thiouracil-5-caboxylate; TEGDMA: Trimethylolpropane trimethacrylate; UDMA: Urethane dimethacrylate; VBATDT: 6-(4-vinylbenzyl-N-propyl) amino-1,3,5-triazine-2,4-dithione. 
Three composite cylinders were tested immediately, while the other three composite cylinders were thermocycled (MSCT-1; Marnucci ME, São Carlos, SP, Brazil) for 5,000 cycles $\left(5 / 55^{\circ} \mathrm{C}\right)$ with a dwell time of $30 \mathrm{~s}$ and tested. SBS test was performed in a universal testing machine (Instron Model 4411; Instron Corporation, Canton, MA, USA) with the shear load applied to resin cylinder base by an orthodontic wire (0.08" diameter) at a crosshead speed of $0.5 \mathrm{~mm} / \mathrm{min}$ until failure. Six SBS measurements were recorded for each cast block; the SBS means for each group were calculated by averaging the three measurements of specimens at 24 $\mathrm{h}$ without thermocycling and three thermocycled ones. The SBS was expressed in MPa.

SBS data analysis used SPSS statistic 21.0 (SPSS Inc.; Chicago, IL, USA) for macOS. Data were analyzed by twoway ANOVA (treatment and thermal cycling) and Tukey post-hoc test at a preset $\alpha=0.05$.

After the SBS test, each sample was gold-sputtered (Desk II; Denton Vacuum Inc., NJ, USA) in order to evaluate the mode of fracture in SEM (JSM-5600LV; JEOL, Tokyo, Japan) at $50 \times$ magnification. The failure mode was classified as follows: "Adhesive" when the metal surface from bonding site was 100\% exposed; "Cohesive" when the fracture involved the flowable composite and "Mixed" when the fracture occurred cohesively within composite and was also "Adhesive" (16).

Results

SBS means and standard deviations of the experimental groups and the results of statistical analysis are presented in the Table 2. Two-way ANOVA demonstrated that there

Table 2. Shear bond strength (MPa) and standard deviation for the experimental groups at $24 \mathrm{~h}$ or after thermal cycling

\begin{tabular}{lcc}
\hline Groups & $24 \mathrm{~h}$ & Thermocycling \\
\hline Control & $11.4 \pm 1.5 \mathrm{~A} \mathrm{~d}$ & $6.9 \pm 2.2 \mathrm{~A} \mathrm{c}$ \\
$\mathrm{AP}$ & $19.6 \pm 1.7 \mathrm{~A} \mathrm{bc}$ & $11.4 \pm 4.3 \mathrm{~B} \mathrm{c}$ \\
$\mathrm{AP}+\mathrm{SB}$ & $23.2 \pm 1.7 \mathrm{~A} \mathrm{ab}$ & $18.8 \pm 3.5 \mathrm{~A} \mathrm{~b}$ \\
$\mathrm{AP}+\mathrm{SU}$ & $22.9 \pm 0.9 \mathrm{~A} \mathrm{ab}$ & $20.1 \pm 4.5 \mathrm{~A} \mathrm{~b}$ \\
$\mathrm{UP}+\mathrm{SB}$ & $22.0 \pm 1.4 \mathrm{~A} \mathrm{ab}$ & $19.2 \pm 2.3 \mathrm{~A} \mathrm{~b}$ \\
$\mathrm{UP}+\mathrm{SU}$ & $25.4 \pm 1.9 \mathrm{~A} \mathrm{a}$ & $26.0 \pm 3.5 \mathrm{~A} \mathrm{a}$ \\
$\mathrm{CP}+\mathrm{SB}$ & $12.6 \pm 1.3 \mathrm{~A} \mathrm{~d}$ & $7.8 \pm 1.2 \mathrm{~A} \mathrm{c}$ \\
$\mathrm{CP}+\mathrm{SU}$ & $12.3 \pm 1.7 \mathrm{~A} \mathrm{~d}$ & $6.7 \pm 1.4 \mathrm{~B} \mathrm{c}$ \\
$\mathrm{SU}$ & $15.7 \pm 0.7 \mathrm{~A} \mathrm{~cd}$ & $7.0 \pm 1.5 \mathrm{~B} \mathrm{c}$ \\
\hline
\end{tabular}

Upper letters compare specimens tested after $24 \mathrm{~h}$ to thermocycled ones (row) and small case letters compare groups (column).

Abbreviations: AP: Alloy Primer; SB: Adper Single Bond 2; SU: Scotchbond Universal; UP: Universal Primer; CP: RelyX Ceramic Primer. were statistically significant differences for the factors "treatment" $(F=73.25, p<0.0001)$ and "thermal cycling" $(F=88.10, p<0.0001)$ and for interaction between the factors ( $F=3.90 ; p=0.0009$ ).

For the 24-h groups, the Tukey's post-hoc test showed that the application of primers (AP and UP) combined with bonding agents (SB and SU) increased significantly the SBS, except when $C P$ was used. There was no significant difference in $\mathrm{SBS}$ values between control group, $\mathrm{CP}$ groups $(\mathrm{CP}+\mathrm{SB}$ and $\mathrm{CP}+\mathrm{SU})$ and $\mathrm{SU}$ only.

For thermocycled groups, the lowest $S B S$ values were found for control group, $\mathrm{AP}, \mathrm{CP}+\mathrm{SB}, \mathrm{CP}+\mathrm{SU}$ and $\mathrm{SU}$ $(6.7 \pm 1.4 \mathrm{MPa}$ to $11.4 \pm 4.3 \mathrm{MPa})$, while the highest SBS was obtained with UP+SB $(26.0 \pm 3.5 \mathrm{MPa})$. Intermediate values were found around $19 \mathrm{MPa}$ for $\mathrm{AP}+\mathrm{SB}, \mathrm{AP}+\mathrm{SU}$ and $\mathrm{UP}+\mathrm{SB}$. Thermal cycling reduced the bond strength for $\mathrm{AP}$, $\mathrm{CP}+\mathrm{SU}$ and $\mathrm{SU}$.

The failure mode of each group is presented in Figure 1. The control group, AP and SU showed 100\% adhesive failures. The UP yielded greater prevalence of mixed failures. Cohesive failures within composite were observed only for the UP+SB group at $24 \mathrm{~h}$.

\section{Discussion}

Both null hypotheses stating that SBS would not be influenced by the primers or multimode adhesive and the thermocycling would not reduce the SBS, were rejected, since some groups with adhesive primers had increased SBS compared to control group and because thermocycling decreased SBS depending on the experimental group. The $A P$ and UP combined with dental adhesives improved the SBS, while the multi-mode and CP primer did not affect the $S B S$ and were not statistically different from control group. The SBS of three groups (AP, $\mathrm{CP}+\mathrm{SU}$ and $\mathrm{SU})$ was reduced after thermocycling compared to their respective 24-h groups.

The high bond strength between metal and composite resin depends on the micromechanical interlocking and physicochemical bonding or a combination of both $(7,10,17,18)$. The micromechanical retention can be obtained by sandblasting with aluminum oxide abrasive particles, while the chemical bonding results from functional monomers of the metal primers, which are able to react and bond to the surface oxide layer of dental alloys $(7,17-19)$. This layer is formed on the surface of most metal alloys exposed to oxygen and/or high temperatures (19).

Before applying alloy primers, the $\mathrm{Ni}-\mathrm{Cr}$ surfaces were sandblasted with aluminum oxide $(50 \mu \mathrm{m})$ to remove the superficial oxide layer, to clean from investment and to increase the bonding area. Sandblasting also standardized the metal surface (19), in order to accurately assess the influence of thermocycling and application of metal primers 
and adhesive system on the SBS of composite resin to $\mathrm{Ni}-\mathrm{Cr}$ metal alloy.

Thermocycling was used to produce aging of metal alloy-composite interfaces, because the temperature variations are able to shrink and expand resin-based materials involved in this interface (adhesives and composite), which may compromise the bond and reduce the bond strength of composite resin to $\mathrm{Ni}-\mathrm{Cr}$ alloy (12). Thus, the bond strength outcomes after thermocycling varied according to the type of metal primer and the used adhesive (6), because these bonding agents present different compositions that maybe interact differently with the oxide layer of the $\mathrm{Ni}-\mathrm{Cr}$ surface (7).

AP metal primer is advised improve the adhesion between resin-based materials to gold, other noble alloys, base metals and titanium. It contains a mixture of VBATDT and 10-MDP. The VBATDT, a thione-thiol tautomer, is effective to promote adhesion between noble metal alloys and resin-based materials. The thione group reacts chemically with metals, while vinyl groups copolymerize with the methacrylate-based resins $(18,20,21)$. 10-MDP can react chemically with chromium oxide of the casting surface, producing strong adhesion $(5,18)$. Bulbul et al. (18) obtained higher SBS values using AP applied to Co$\mathrm{Cr}$ metal alloy, but after thermocycling the bond strength values decreased significantly, which was not considered durable and reliable.

In this study, when the AP was used in combination with SB or SU, there were no SBS differences between the at $24 \mathrm{~h}$ and after thermocycling. However, when AP was applied alone, the SBS decreased after thermocycling. These results suggested that AP needs an adhesive layer over it to maintain a stable adhesion. The fracture mode was 100\% adhesive, but for AP combined with adhesive systems, some mixed fractures were observed.

The SBS of AP to $\mathrm{Ni}-\mathrm{Cr}$ alloy used without adhesive coating showed no significant difference when this metal primer was combined with an adhesive. However, the same results were not observed after thermocycling, in which the combination of AP with SB or SU presented higher SBS than AP alone. Also, the SBS of combined use of AP and adhesives did not decrease after thermocycling, as occurred for AP used without adhesive coating. Thus, these results indicate that AP needs an adhesive layer over it to maintain a stable adhesion. The fracture mode was 100\% adhesive, but when AP was combined with adhesive systems some mixed fractures were observed.

CP contains MPS, which is a silane coupling agent. Its manufacturer indicates $\mathrm{CP}$ for the repair of damaged ceramic crowns, bridges and PFM indirect restorations. The results did not show any advantage of using $\mathrm{CP}$ combined with adhesives and the SBS was similar to control group at $24 \mathrm{~h}$ and after thermocycling. Di Francescantonio et al. (5) used CP combined with resin cement and they did not find good results in bond strength to $\mathrm{Ni}-\mathrm{Cr}$. However, another study demonstrated that $\mathrm{CP}$ was effective when applied to conditioned titanium. According to the authors, $\mathrm{CP}$ can improve the wettability, which may be responsible for increasing the bond strength to that alloy (19).

UP is an adhesive primer indicated for the repair of ceramics, metal alloys, PFM and composite materials. It has also been used for bonding denture resin to metal base. UP contains MTU- 6 and MAC- 10 . MTU- 6 is a thiouracil monomer and its hexyl group produces a chemical bond between resin-based materials and precious metals $(5,6)$. MAC-10 is a carboxylic acid monomer, which is considered

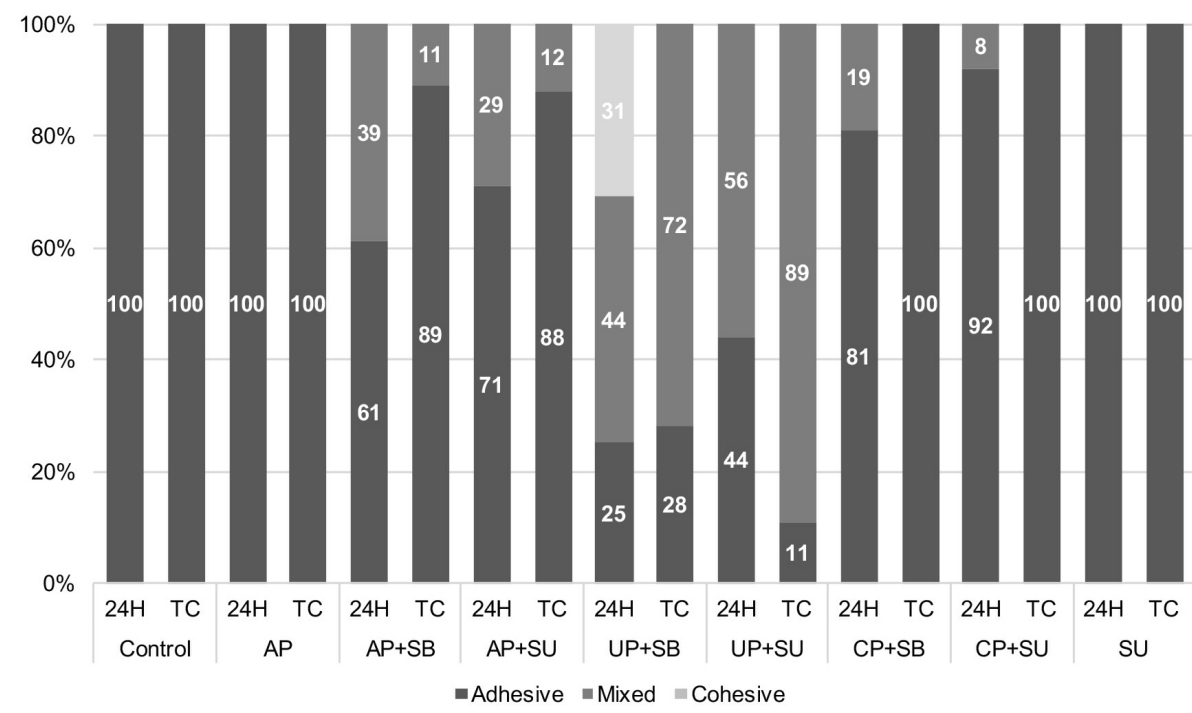

Figure 1. Distribution (\%) of failure modes among experimental groups after $24 \mathrm{~h}(24 \mathrm{H})$ and after thermal cycling (TC). 
hydrolytically stable because its spacer group contains 10 carbon atoms. Some studies have shown that carboxylic acid monomer is able to react with the chromium oxide, insuring proper bond strength and stability over time even after in vitro thermocycling $(22,23)$, which corroborates the results of this study. The combination of UP with MDP-containing adhesive (SU) yielded one of the best SBS results at $24 \mathrm{~h}$; additionally, after thermocycling this experimental group showed the highest SBS. Thus, it may be speculated that there was no competitive relationship between MAC-10 and 10-MDP.

Higher SBS values presented for UP groups modified the failure pattern, which was predominantly mixed failure at $24 \mathrm{~h}$ and after thermocycling. The flowable composite remaining at $\mathrm{Ni}-\mathrm{Cr}$ bonding area may be due to the chemical interaction between the carboxylic functional group of the MAC-10 monomer and $\mathrm{Ni}-\mathrm{Cr}$ alloy.

SU is a multi-mode adhesive system that contains 10-MDP monomer. According to the manufacturer, it can be used for intraoral repair of existing indirect restorations and as a primer for zirconia, alumina, other metals and glass ceramic restorations. The results showed that the SBS of SU to Ni-Cr alloy was not effective. Taira et al. (8) tested an experimental primer containing MDP dissolved in acetone and the initial bond strength values were adequate (20.6 MPa). However, the SBS decreased significantly following thermocycling and those authors concluded that is difficult to obtain a durable bonding using phosphoric acid derivatives solely. A recent study shows that the silane-containing Universal adhesive did not seem very effective and stable, and recommended the use of a separate silane primer to achieve enough silane-coupling effect (24). In addition, studies show that multi-mode systems may absorb water even after curing, which degrades the polymer network, reducing the bond strength $(15,25)$. The lack of interaction of $\mathrm{SU}$ with $\mathrm{Ni}-\mathrm{Cr}$ alloy reflects in the failure mode that was 100\% adhesive.

Adhesive monomers present three different parts. The first is the functional group that is responsible for bonding to metal alloys. The second part is the polymerizable group, which reacts with resin-based materials. The third is the hydrophobic portion, which ensures hydrolytic stability for the monomer $(6,7,12,22)$. MTU- 6 and VBATDT monomers have different lengths of spacer chain, generating different degrees of hydrophobicity, which may explain the stability of the bond strength after thermocycling for UP groups. The mix of MDP with EP3MA and EP8MA (two sulfur-containing monomers whose structures have different lengths of spacer chain) resulted in a monomer with greater length of spacer chain that was less affected by thermal cycling (13).

Studies have shown that the combined use of a sulfurcontaining monomer and a phosphate monomer improved the bond strength of noble and base metal dental alloys $(12,13)$. However, the combination of a primer sulfurcontaining monomer, carboxylic acid functional monomers and a 10-MDP-containing adhesive system must be further investigated to ensure that the bonding of resin-based materials to metal alloys using adhesive primers is reliable and predictable.

The results suggested that two metal primers (Alloy Primer and Universal Primer) combined with dental adhesives can improve the bond strength of a flowable composite to $\mathrm{Ni}-\mathrm{Cr}$ alloy. These combinations yielded the highest SBS values after thermocycling.

\section{Resumo}

Este estudo avaliou os efeitos de três primers para metais e um sistema adesivo multi-mode na resistência da união por cisalhamento (SBS) de um compósito resinoso de baixa viscosidade a uma liga niquel-cromo $(\mathrm{Ni}-\mathrm{Cr})$. Noventa placas $\mathrm{Ni}-\mathrm{Cr}$ foram divididas em 9 grupos $(n=10)$. As superfícies foram jateadas com $\mathrm{Al}_{2} \mathrm{O}_{3}$ e condicionadas com três primers adesivos: Alloy Primer (AP), Universal Primer (TP) e Rely X Ceramic Primer (CP) e um adesivo multi-mode (Scotchbond Universal, SU). Os adesivos Adper Single Bond Plus (SB) e SU foram combinados com os primers para metais. 0 grupo controle não recebeu nenhum tipo de tratamento superficial. Os grupos foram: $A P, A P+S B, A P+S U, T P+S B, T P+S U, C P+S B$, $\mathrm{CP}+\mathrm{SU}$ e $\mathrm{SU}$. Cilindros de resina foram construidos na superfície da liga. Após $24 \mathrm{~h}$, metade dos espécimes foi submetido ao SBS, a outra metade foi termociclada previamente. Os dados foram analisados pelos testes ANOVA dois fatores e Tukey $(\alpha=0.05)$. Os tipos de fraturas foram determinados utilizando microscopia eletrônica de varredura (MEV). Os maiores valores de SBS foram obtidos com AP e TP combinados com adesivos após $24 \mathrm{~h}$ e o menor valor foi obtido no grupo controle. A ciclagem térmica reduziu a SBS para AP, CP+SU e SU. Combinação entre TP e SU resultou em altos valores de SBS após termociclagem. Os grupos TP apresentaram todos os modos de fratura e alta incidência de fraturas mistas. 0 uso dos primers AP e UP para metais antes da aplicação dos sistemas adesivos SU e SB aumentou a SBS entre o $\mathrm{Ni}-\mathrm{Cr}$ e a resina composta. Essa combinação entre primers e adesivos mostrou os maiores valores de SBS após a termociclagem.

\section{References}

1. dos Santos JG, Fonseca RG, Adabo GL, dos Santos Cruz CA. Shear bond strength of metal-ceramic repair systems. J Prosthet Dent 2006;96:165-173.

2. Galiatsatos AA. An indirect repair technique for fractured metalceramic restorations: A clinical report. J Prosthet Dent 2005;93:321323.

3. Hickel R, Brüshaver K, Ilie N. Repair of restorations - Criteria for decision making and clinical recommendations. Dent Mater The Academy of Dental Materials 2013;29:28-50.

4. Yesil ZD, Karaoglanoglu S, Akyil MS, Seven N. Evaluation of the bond strength of different composite resins to porcelain and metal alloy. Int J Adhes Adhes 2007;27:258-262.

5. Di Francescantonio M, de Oliveira MT, Garcia RN, Romanini JC, da Silva NRFA, Giannini M. Bond strength of resin cements to $\mathrm{Co}-\mathrm{Cr}$ and $\mathrm{Ni}-\mathrm{Cr}$ metal alloys using adhesive primers. J Prosthodont 2010;19:125-129.

6. Minami H, Murahara S, Suzuki S, Tanaka T. Effects of metal primers on the bonding of an adhesive resin cement to noble metal ceramic alloys after thermal cycling. J Prosthet Dent 2011;106:378-385.

7. Fonseca RG, de Almeida JGDSP, Haneda IG, Adabo GL. Effect of metal primers on bond strength of resin cements to base metals. J Prosthet Dent 2009;101:262-268.

8. Taira Y, Imai Y. Primer for bonding resin to metal. Dent Mater 1995;11:2-6. 
9. Tanaka T, Nagata K, Takeyama M, Atsuta M, Nakabayashi N, Masuhara E. 4-META opaque resin - A new resin strongly adhesive to nickelchromium alloy. J Dent Res 1981;60:1697-1706.

10. Almilhatti $\mathrm{HJ}$, Giampaolo ET, Vergani $\mathrm{CE}$, Machado $\mathrm{AL}$, Pavarina $\mathrm{AC}$, Betiol EA. Adhesive bonding of resin composite to various $\mathrm{Ni}-\mathrm{Cr}$ alloy surfaces using different metal conditioners and a surface modification system. J Prosthodont 2009;18:663-669.

11. Kadoma Y. Chemical structures of adhesion promoting monomers for precious metals and their bond strengths to dental metals. Dent Mater J 2003;22:343-358.

12. Taira $Y$, Kamada $K$, Atsuta $M$. Effects of primers containing thiouracil and phosphate monomers on bonding of resin to $\mathrm{Ag}-\mathrm{Pd}$-Au alloy. Dent Mater J 2008;27:69-74.

13. Kadoma Y. Surface treatment agent for dental metals using a thiirane monomer and a phosphoric acid monomer. Dent Mater J 2002;21:156169.

14. Makishi $P$, André $C B$, Ayres $A$, Martins AL, Giannini M. Effect of storage time on bond strength and nanoleakage expression of universal adhesives bonded to dentin and etched enamel. Oper Dent 2016;41:305-317.

15. Marchesi G, Frassetto $\mathrm{A}$, Mazzoni $\mathrm{A}$, Apolonio F, Diolosà M, Cadenaro $\mathrm{M}$, et al.. Adhesive performance of a multi-mode adhesive system: 1-year in vitro study. J Dent 2014;42:603-612.

16. Sanohkan S, Urapepon S, Harnirattisai C, Sirisinha C, Sunintaboon P. Shear bond strength between autopolymerizing acrylic resin and $\mathrm{Co}-\mathrm{Cr}$ allaoy using different primers. Dent Mater J 2012;31:765-771.

17. Almilhatti HJ, Giampaolo ET, Vergani CE, Machado AL, Pavarina AC. Shear bond strength of aesthetic materials bonded to $\mathrm{Ni}-\mathrm{Cr}$ alloy. J Dent 2003;31:205-211.
18. Bulbul M, Kesim B. The effect of primers on shear bond strength of acrylic resins to different types of metals. J Prosthet Dent 2010;103:303-308.

19. Di Francescantonio $M$, Oliveira MT de, Daroz LGD, Henriques GEP, Giannini M. Adhesive bonding of resin cements to cast titanium with adhesive primers. Braz Dent J 2012;23:218-222.

20. Kojima $K$, Kadoma Y IY. Adhesion to precious metals utilizing triazine dithione derivative monomer. J Jpn Soc Dent Mater 1987;6:702-707.

21. Silikas N, Wincott PL, Vaughan D, Watts DC, Eliades G. Surface characterization of precious alloys treated with thione metal primers. Dent Mater 2007;23:665-673.

22. Van Landuyt KL, Snauwaert J, De Munck J, Peumans M, Yoshida $Y$, Poitevin A, et al.. Systematic review of the chemical composition of contemporary dental adhesives. Biomaterials 2007;28:3757-3785.

23. Giannini M, Makishi P, Ayres APA, Vermelho PM, Fronza BM, Nikaido T, et al.. Self-etch adhesive systems: a literature review. Braz Dent J 2015;26:3-10.

24. Yoshihara K, Nagaoka N, Sonoda A, Maruo Y, Makita Y, Okihara T, et al.. Effectiveness and stability of silane coupling agent incorporated in "universal" adhesives. Dent Mater 2016;32:1218-1225.

25. Vermelho PM, Reis AF, Ambrosano GMB, Giannini M. Adhesion of multimode adhesives to enamel and dentin after one year of water storage. Clin Oral Investig 2016 [Epub ahead of print. DOI: 10.1007/ s00784-016-1966-1].

Received September 6, 2016 Accepted January 23, 2017 